\title{
Risk assessment on railway transportation of hazardous materials
}

\author{
S. Cafiso, A. Di Graziano \& N. Di Blasi \\ Department of Civil and Environmental Engineering, University of \\ Catania, Italy
}

\begin{abstract}
The transportation of hazardous materials involves a non-negligible quantity of goods carried by both road and rail. Moreover, considering today's greater environmental awareness and the large anthroprical presence, the release of hazardous materials in an accident assumes an ever growing importance. For this reason a risk assessment, considered as the product of the probability of an incident occurring and the gravity of its consequences, is necessary. In the present work, a model to determine risk levels generated by an accident involving the transportation of hazardous materials by rail is presented. The accident risk assessment model takes into account the influence of (1) the main causes of defects (track structure, line characteristics, wagon characteristics, railway operation and traffic system), (2) the probability of a container breaking with the consequent release of dangerous substances during transport and (3) the number of people potentially exposed to the consequences of the accident. Finally, the presentation of a case study implemented using a Geographical Information System made it possible to highlight the potential and effectiveness of the proposed procedure. It is able to supply information and quantitative data which can be used to characterise improvement works and/or transportation procedures and routes in order to minimise the risks connected to the transportation of hazardous materials.
\end{abstract}

Keywords: risk assessment, accidents, hazardous materials, railway, GIS.

\section{Introduction}

The problems of environmental impact which have always accompanied industrial development and the economic benefits associated with it, can be 
symbolically illustrated by the production, storage and distribution of products whose release can produce serious consequences for both the environment and human health.

The crucial moments connected to the production of potentially harmful substances have been well known for some time, not only within the factory but also during the transportation phase which is the cause of about $40 \%$ of all accidents [1]. This consideration is aggravated by the fact that nowadays the transport of hazardous materials (hazmat) constitutes a large percentage of the total movement of goods (table 1) with a share as high as $20 \%$ in the case of road transport.

Table 1: $\quad$ Modal share of dangerous goods transported (source: ISTAT 2002).

\begin{tabular}{|c|c|c|c|}
\hline $\begin{array}{c}\text { Geographical } \\
\text { area }\end{array}$ & Transport system & $\begin{array}{c}\text { Quantity exported } \\
(1000 \times \mathrm{x})\end{array}$ & $\begin{array}{c}\text { Quantity imported } \\
(1000 \mathrm{x} \mathrm{t})\end{array}$ \\
\hline \multirow{4}{*}{$\begin{array}{c}\text { European } \\
\text { Union }\end{array}$} & maritime & 6,773 & 5,204 \\
\cline { 2 - 4 } & railway & 558 & 647 \\
\cline { 2 - 4 } & road & 2,106 & 3,529 \\
\cline { 2 - 4 } & air & 2 & 6 \\
\cline { 2 - 4 } & $\begin{array}{c}\text { Other (oil and gas pipeline, } \\
\text { etc.) }\end{array}$ & 192 & 7560 \\
\cline { 2 - 4 } & Total & 9,631 & 16,946 \\
\hline
\end{tabular}

The data in table 1 highlight an evident disparity between the two principal systems of land transport (road-rail), a difference that appears even wider if national figures are analysed [2].

Data clearly demonstrate the present inadequate appeal of railway transport for the transportation of hazmat despite the fact that it is recognised as being much safer than road transport.

From this point of view, it becomes necessary to identify uniform parameters to evaluate the risk linked to the transportation of dangerous materials, so as to objectively define those routes, modes and transport characteristics which involve the minimum risk.

\section{Risk assessment model for the rail transportation of hazmat}

At present, in Italy, the transportation of hazmat by rail is not subject to any special restrictions, in that safety depends on the checking of the vehicles conditions according to the RID regulations [3], as well as on the rules governing railway operating. On the other hand, an approach based on risk analyses separates the problem into three independent factors:

Dangerousness $(P)$ : related to the possibility of an event of a given intensity taking place in a given reference period;

Vulnerability $(V)$ : relating to how likely it is that the system will be damaged by such an event;

Exposure (E): referring to the magnitude and gravity of the consequences suffered by the population, the environment and the economy.

The formulation of these three factors normally defines the level of risk (R): 


$$
\mathrm{R}=\mathrm{P} \times \mathrm{V} \times \mathrm{E}
$$

In the case under examination, the factors $\mathrm{P}, \mathrm{V}$ and $\mathrm{E}$ take on the following meanings:

P: factor related to the possibility of an accident taking place along the line;

$\mathrm{V}$ : factor related to the possibility of a container breaking with the subsequent release of the transported materials;

E: factor related to the number of people potentially at risk of serious injury as a result of the accident.

Starting from these bases, the objective of the research was to relate the risk assessment to the line characteristics, the kind of wagons and railway operation and with the population distribution in the area around the railway line.

More specifically, the hazmat transport risk $(\mathrm{R})$ was expressed as the product of the dangerousness index of the line segment $\left(\mathrm{P}_{\mathrm{t}}\right)$, depending on its operation characteristics, the release factor $\left(V_{R}\right)$, depending on the train speed and typology of container, and the exposure index $\left(\mathrm{E}_{\mathrm{i}}\right)$, depending on the kind of material transported and the surrounding environment:

$$
\mathrm{R}=\mathrm{P}_{\mathrm{t}} \times \mathrm{V}_{\mathrm{R}} \times \mathrm{E}_{\mathrm{i}}
$$

Defining different values of $\mathrm{R}$ for each line segment allows a comparative analysis to be carried out, so as to identify those segments with the highest risk. Priority can then be given to prevention and/or mitigation of the consequences, or rather, operating solutions (reductions in train speed, improvements in the traffic systems, superstructure maintenance, etc) aimed at reducing the possibility of an accident leading to the release of hazmat. Moreover, it is also possible to quantify a global value for each route so as to establish those routes which can minimise risk.

\subsection{Dangerousness Index of the line segment $\left(P_{t}\right)$}

The first parameter for risk assessment has been linked to the probability that with given infrastructure, working and wagon type conditions an accident can take place on a specific segment of railway. More specifically, the analysis of studies on railway accident carried out in different countries $[1,4,5]$, made it possible to highlight how the most frequent cause of an accident is a derailment (fig 1).

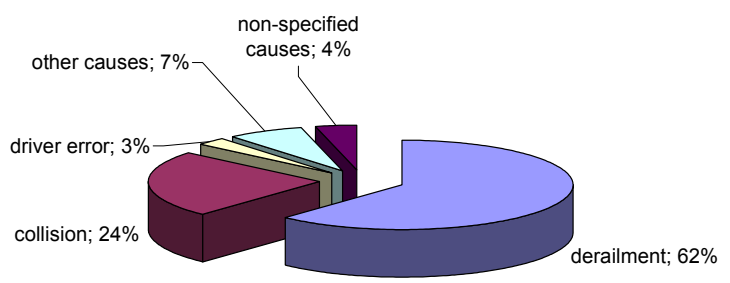

Figure 1: $\quad$ Frequency distribution of the causes of railway accidents [7]. 
As there is a high risk that hazmat in transport will be released in this kind of accident [6]. Therefore the following analyses were carried out with particular reference to a derailment accident. Five sectors have been identified to which defects, causing a derailment, can be associated: (1) track structure, (2) line characteristics, characteristics.
(3) traffic system,
(4) railway
operation,
(5) wagon

The $\mathrm{P}_{\mathrm{t}}$, was, therefore, quantitatively defined according to the following relation:

where:

$$
\mathrm{Pt}=\Sigma \mathrm{p}_{\mathrm{i}} \times \mathrm{w}_{\mathrm{i}}
$$

$\mathrm{p}_{\mathrm{i}}=$ the incidence of the $\mathrm{i}$-th sector on the possible accident $\left(0<\mathrm{p}_{\mathrm{i}}<1\right)$;

$\mathrm{w}_{\mathrm{i}}=$ value associated to the efficiency of the $\mathrm{i}$-th sector $\left(0<\mathrm{w}_{\mathrm{i}}<1\right)$;

The $\mathrm{p}_{\mathrm{i}}$ weights, associated with the five sectors could be deduced from data relating to the frequency with which derailments take place and their gravity. In the present work, the unavailability of exhaustive data referring to the Italian network made it necessary to refer to information coming from the accident data bank of the Federal Rail Administration (FRA) [4]. Referring only to derailments, it was possible to calculate the product $\mathrm{H}$ of the gravity (average number of wagons derailed) and the accident frequency $\left(\mathrm{n}^{\circ}\right.$ of accidents registered) for each category of defect.

The $\mathrm{p}_{\mathrm{i}}$ of each sector was then determined as the relationship between the sum of the $\mathrm{H}$ factors of the defects associated with it and the total $\mathrm{H}$ value (fig 2).

As regards the calculation of the $\mathrm{w}_{\mathrm{i}}$ parameters with which to evaluate the efficiency of the network as compared to the probability of a derailment, specific criteria were defined for each of the previously identified segments. They are reference criteria based on consensus with railway operators which could be modified without changing the logic of the model.

\subsubsection{Track structure parameter $\left(\mathrm{w}_{1}\right)$}

The state of the track can be judged by the geometrical conditions of the railway line. More specifically, the maintenance of the railway track on the Italian network is carried out identifying four levels of rail quality, defined according to longitudinal and transversal level defects, as well as alignment defects.

$1^{\text {st }}$ quality level: track in excellent condition;

$2^{\text {nd }}$ quality level: track in good condition, some deterioration noted;

$3^{\text {rd }}$ quality level: (intervention phase): rail quality index values (IQB) such that maintenance is necessary;

$4^{\text {th }}$ quality level: IQB values such that use must be restricted. These threshold values depend on the maximum speed over the segment under examination [8].

The value of $\mathrm{w}_{1}$ grows linearly from 0 to 1 in accordance with the variation of IQB from 0 to the threshold values.

\subsubsection{Line characteristics parameter $\left(\mathrm{w}_{2}\right)$}

Line characteristic factors to which different levels of accident probability can be associated depend, firstly, on interference deriving from the trains themselves 
(single or double track) and secondly on the line alignment.

Therefore, the $\mathrm{w}_{2}$ parameter was related to the type of rail $\left(\mathrm{w}_{2 \mathrm{a}}\right)$ and to the line performance level $\left(\mathrm{w}_{2 \mathrm{~b}}\right)$ by means of the following relation:

$$
\mathrm{w}_{2}=0.8 \mathrm{w}_{2 \mathrm{a}}+0.2 \mathrm{w}_{2 \mathrm{~b}}
$$

The parameter connected to the type of rail assumes the least favourable condition $\left(\mathrm{w}_{2 \mathrm{a}}=1\right)$ in the case of a single line, while a double line represents the safest situation $\left(\mathrm{w}_{2 \mathrm{a}}=0.1\right)$. The degree of line performance was correlated to the efficiency of the line $\left(\mathrm{w}_{2 \mathrm{~b}}\right)$ expressed as degree of performance $(\mathrm{G}=1 \div 31)$, associating a value of 1 to the maximum $(\mathrm{G}=31)$, the value of 0.1 to the minimum degree of performance $(\mathrm{G}=1)$ and identifying a linear relationship for the intermediate values.

\begin{tabular}{|c|c|c|c|c|c|c|c|}
\hline Sector & Defect & FREQ & GRAV & $\mathbf{H}$ & $\neg \mathrm{H}$ & Htot & weigth $\mathrm{pi}_{\mathrm{i}}$ \\
\hline \multirow{11}{*}{ 1. track strucutre } & Rail defect at bolted joint & 50 & 15.5 & 775 & \multirow{11}{*}{24816} & \multirow{47}{*}{47801} & \multirow{11}{*}{0.52} \\
\hline & Joint bar defects & 68 & 15.2 & 1034 & & & \\
\hline & Other rail and joint defects & 79 & 15.1 & 1193 & & & \\
\hline & Turnout defects - frogs & 13 & 14 & 182 & & & \\
\hline & Broken rails or welds & 800 & 12.7 & 10160 & & & \\
\hline & Buckled Track & 254 & 10.2 & 2591 & & & \\
\hline & Mix track and structure defects & 110 & 8.7 & 957 & & & \\
\hline & Wide gauge & 353 & 7.8 & 2753 & & & \\
\hline & Roadbed defects & 130 & 7 & 910 & & & \\
\hline & Turnout defects - switches & 179 & 6.6 & 1181 & & & \\
\hline & Track geometry & 531 & 5.8 & 3080 & & & \\
\hline \multirow{3}{*}{ 2. line characteristics } & Obstructions & 92 & 12.2 & 1122 & \multirow{3}{*}{5687} & & \multirow{3}{*}{0.12} \\
\hline & Other miscellanious & 289 & 10.9 & 3150 & & & \\
\hline & Track -train interation & 221 & 6.4 & 1414 & & & \\
\hline \multirow{4}{*}{ 3. traffic system } & Mainline rules & 16 & 9.4 & 150 & \multirow{4}{*}{669} & & \multirow{4}{*}{0.01} \\
\hline & Radio communications error & 10 & 6.1 & 61 & & & \\
\hline & Signal failures & 20 & 10.7 & 214 & & & \\
\hline & Switching rules & 42 & 5.8 & 244 & & & \\
\hline \multirow{9}{*}{ 4. railway operation } & Brake operation (main line) & 63 & 9.5 & 599 & \multirow{9}{*}{6188} & & \multirow{9}{*}{0.13} \\
\hline & Misc. human factors & 49 & 9.4 & 461 & & & \\
\hline & Lading problems & 162 & 7 & 1134 & & & \\
\hline & Brake operation (other line) & 20 & 8.7 & 174 & & & \\
\hline & Train handling (excl. brakes) & 288 & 8.5 & 2448 & & & \\
\hline & Train speed & 76 & 6.2 & 471 & & & \\
\hline & Failure to obey/display signals & 16 & 5.8 & 93 & & & \\
\hline & Use of switches & 139 & 4.9 & 681 & & & \\
\hline & Handbrake operations & 26 & 4.9 & 127 & & & \\
\hline \multirow{20}{*}{ 5. wagon characteristics } & Loco electrical and fires & 8 & 20 & 160 & \multirow{20}{*}{10442} & & \multirow{20}{*}{0.22} \\
\hline & UDE (car or loco) & 12 & 11 & 132 & & & \\
\hline & Loco trucks/bearings/wheels & 19 & 8.9 & 169 & & & \\
\hline & Track/train interation (hunting) & 58 & 8.5 & 493 & & & \\
\hline & Broken wheels & 175 & 8 & 1400 & & & \\
\hline & Stiff truck & 96 & 7.9 & 758 & & & \\
\hline & All other car defects & 55 & 7.7 & 424 & & & \\
\hline & Truck structure defects & 17 & 7.5 & 128 & & & \\
\hline & Air hose defect & 17 & 7 & 119 & & & \\
\hline & All other locomotive defects & 19 & 6.7 & 127 & & & \\
\hline & Coupler defects & 98 & 6.6 & 647 & & & \\
\hline & Other axle/journal defects & 62 & 6.4 & 397 & & & \\
\hline & Other wheel defects & 169 & 6.3 & 1065 & & & \\
\hline & Bearing failure & 455 & 6.2 & 2821 & & & \\
\hline & Sidebearing, suspension defects & 131 & 6.1 & 799 & & & \\
\hline & Other brake defects & 30 & 5.2 & 156 & & & \\
\hline & Brake rigging defect & 31 & 4.7 & 146 & & & \\
\hline & Centerplate/carbody defects & 105 & 4.6 & 483 & & & \\
\hline & TOFC/COFC defects & 6 & 2.5 & 15 & & & \\
\hline & Handbrake defects & 2 & 2 & 4 & & & \\
\hline
\end{tabular}

Figure 2: Weights attributed to the five sectors.

\subsubsection{Traffic system parameter $\left(\mathrm{w}_{3}\right)$}

As regards the possible traffic systems used on Italian railways, the variation in value of the $\mathrm{w}_{3}$ parameter was defined with reference to optimal conditions, that is when signals are transmitted to the driver's cab. Without this facility the traffic system has a greater influence on the probability of an accident, so it was 
considered a doubling of the following value of $\mathrm{w}_{3}$. Generally, the automatic block signal $(\mathrm{BAB})$ is considered as providing the maximum safety conditions $\left(\mathrm{w}_{3}=0.1\right)$, while the telephonic signal (BT) is seen as being the least efficient $\left(\mathrm{w}_{3}=1\right)$. The other operating systems were evaluated according to their degree of automation and complexity so, for example, the same weight $\left(\mathrm{w}_{3}=0.4\right)$ was assigned to both the manual electric block signal (BEM) and the axles count block signal (BCA) because they both require a visual check by or intervention on the part of the driver. Lower safety conditions were assigned to the fixed current block ( $\left.\mathrm{Bcf}, \mathrm{w}_{3}=0.25\right)$ and the coded current block $\left(\mathrm{Bcc}, \mathrm{w}_{3}=0.15\right)$.

\subsubsection{Railway operation parameter $\left(\mathrm{w}_{4}\right)$}

Human error is the element that, more than any other, characterises the link between operation and accident probability. For this reason the $\mathrm{w}_{4}$ parameter has been associated to the maximum speed over the line $\left(\mathrm{w}_{4 \mathrm{a}}\right)$ and to the number of level crossings along it $\left(\mathrm{w}_{4 \mathrm{~b}}\right)$, elements which influence, to different degrees, the amount of driver attention necessary:

$$
\mathrm{w}_{4}=0.8 \mathrm{w}_{4 \mathrm{a}}+0.2 \mathrm{w}_{4 \mathrm{~b}}
$$

More specifically, parameter $\mathrm{w}_{4 \mathrm{a}}$ increases as the maximum speed allowed on that segment increases. The $\mathrm{w}_{4 \mathrm{~b}}$ parameter varies linearly according to the number of level crossings present along the segment under investigation.

\subsubsection{Wagon characteristics parameter $\left(w_{5}\right)$}

Statistics on railway accidents highlight that wagon defects are an important element in the possibility of a derailment $\left(\mathrm{p}_{5}=0.22\right)$. The condition of a wagon can be considered by taking into account its age, but even more so on the basis of when the last maintenance check took place. Therefore, parameter $\mathrm{w}_{5}$ assumes a value of between 0.1 and 1 according to the age and maintenance of the wagon.

\subsection{Probability of hazardous material release $\left(V_{r}\right)$}

In risk analyses connected with the transportation of hazmat the probability of release $\left(V_{r}\right)$ represents the system vulnerability factor. The parameters that most greatly influence the probability of a release of hazmat can be classified into the following elements:

- type of material transported: it has been seen [1] that there is the greatest probability of release when inflammable liquids are transported (class 3 in the RID classification), while gaseous and corrosive materials present a lesser probability (classes 2 and 8).

- quantity of material transported: there is a greater probability of release when the container is completely full. Assuming that the $80 \%$ limit for maximum container content is respected, this factor can be disregarded.

- modality of transport: the data to be considered are the construction features of the container and more particularly its planned storage pressure. Pressurised containers are thicker and have a greater mechanical resistance in an accident. With this in mind, it was evaluated that after an accident, $V_{R}$ is three times 
higher for atmospheric pressure containers compared to pressurised containers [9]. The kind of storage (tank wagon or container) does not have any influence on the release of substances under the same conditions of transportation and planned pressure.

- train speed: an analysis [4], carried out on more than 800 derailments in which at least one wagon containing hazmat was damaged, highlighted the existence of a linear relationship between speed and the average number of derailed carriages and/or the average fraction of wagons that released hazardous material.

Therefore, referring to the probability of release that characterises the line, the value of $V_{R}$ was estimated only on the basis of the maximum speed allowed for the stretch, using the experimental relation shown in figure 3.

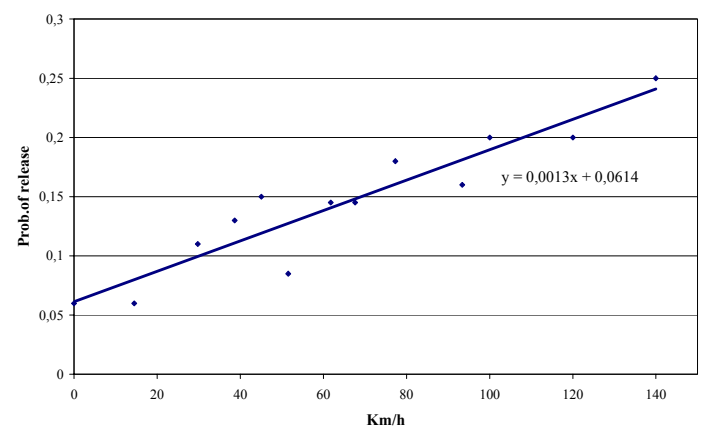

Figure 3: Calculation of VR according to speed [4].

\subsection{Exposure Index (E)}

The effects of an accident involving dangerous goods can be estimated in terms of the exposed population, sensitive environmental areas affected and loss of production.

To quantify exposure correlated to a release of hazmat in the environment, it is necessary to bear in mind that such a discharge can develop in a variety of different ways. The events that can follow on from an accident which involves a vehicle transporting hazmat, can be divided into the following types: fire (jet, pool, flash, fireball), vapour cloud explosion (VCE), diffusion of a toxic cloud, spilling of liquid substances.

On the basis of the type of material being transported it is possible to identify the diverse probabilities of these events occurring [10]. The model to adopt in order to simulate the evolution and diffusion of an event, depends on the kind of environment involved (air, water, land) as well as the characteristics of the discharge. Therefore, it is possible to refer to different dispersion model connected to heavy gas, light gas and liquid substance or to different fire and explosion simulation models.

With regard to the latter two types of event it should be underlined that their relevance, in terms of the number of victims involved, is mainly connected to accidents in tunnels, or more particularly, inside stations. Scenarios that predict 
fires and/or explosions in the 'open air' lead to limited exposure evaluations over a reduced area as compared to those involved by the dispersion of toxic or harmful gases into the atmosphere. Instead, as far as the problem of the spilling of hazardous substances is concerned, the extent of exposure concerns mainly environmental pollution.

Therefore, by way of example, this article reports a model for determining exposure connected with the release into the atmosphere of toxic substances, in that this kind of event has the greatest probability of affecting human health.

When hypothesising the spread of a toxic cloud, in order to identify the extension of the area affected, a Gaussian model for continuous punctiform emissions and heavy gases was used.. The relation for use with heavy gases was:

$$
X_{M A X}=\left(\frac{Q}{0.2 \cdot C \cdot \pi \cdot a^{2} \cdot U}\right)^{\frac{1}{2 b}}
$$

The eqn (6) permits to calculate, for a given minimum level of concentration $\mathrm{C}[\mathrm{g} / \mathrm{m} 3]$, the maximum distance of the diffusion $\mathrm{X}_{\mathrm{MAX}}$ according to wind direction, given the experimental constants ' $\mathrm{a}$ ' and ' $\mathrm{b}$ ' related to the atmospheric stability class, the entity of the emission $\mathrm{Q}[\mathrm{g} / \mathrm{s}]$ and wind speed $\mathrm{U}[\mathrm{m} / \mathrm{s}]$.

The extent of the affected area can be defined according to two limits:

LC50 $=$ the minimum concentration which, if inhaled, proves lethal in 50\% of those exposed for 30 minutes (Lethal Concentration)

IDLH $=$ the concentration which poses a health risk in those exposed for periods of time longer than 30 minutes (Immediately Dangerous for Life and Health).

The identification of the affected area permits the estimation of the exposure connected to the accident in terms of the population living within the area.

\section{Risk Evaluation for the transportation of hazmat}

In order to underline the applicability of the method, a case study is proposed which applies the risk assessment to the transportation of chlorine along the stretch of railway line between Catania and Siracusa (Sicily, Italy) that is one of the main petrochemical industrial areas in the country. The choice of chlorine as the hazardous material to be transported was made in order to highlight the large scale effects of an accident involving the release of a highly toxic cloud.

The risk calculation for the stretch was carried out in a GIS environment. The line is characterised by about $70 \mathrm{~km}$ of railway track, which were subdivided into 15 homogeneous sections according to the features of the line and the traffic system $\left(\mathrm{P}_{\mathrm{t}}\right.$ and $\mathrm{V}_{\mathrm{R}}$ factors constant).

On the basis of this data the efficiency of the single $\mathrm{w}_{\mathrm{i}}$ segments was calculated. The wagon parameter $\mathrm{w}_{5}$ was assumed equal to 0.1 , with the aim of further highlighting the effect of factors linked to the line characteristics. Once the values of $\mathrm{w}_{\mathrm{i}}$ were known, applying the eqn (3) and using the values of $\mathrm{p}_{\mathrm{i}}$ in figure 3 as weights, it was possible to calculate the dangerousness index $P_{t}$ of the line for each of the homogenous segment. 
The factor relating to the probability of a release along the line $V_{R}$ was estimated for each homogenous segment, using the experimental relation shown in figure 4, according to the maximum speed allowed along the section.

Finally, so as to completely define the risk, the exposure calculation $\mathrm{E}$ was carried out with reference to the IDLH concentration level, which for chlorine is estimated as being equal to $0.073 \mathrm{~g} / \mathrm{m}^{3}$. On the basis of this toxicity index and referring to meteorological data coming from Catania airport (West, $\mathrm{U}=4.21 \mathrm{~m} / \mathrm{s}$ ), the extent of the affected area $\mathrm{X}_{\mathrm{MAX}}$ was calculated using the eqn (6) as being equal to $5,000 \mathrm{~m}$. To calculate exposure in terms of the resident population potentially hit by the accident, the whole line was subdivided into fixed segment $(1 \mathrm{~km})$, attributing to each an exposure level equal to the number of residents in the area, identified by a buffer of $5 \mathrm{~km}$ as compared to the axis of the line. Working in this way, it was possible to obtain the risk value for the transport of chlorine connected to each kilometre of the CT-SR railway line (fig $4)$.

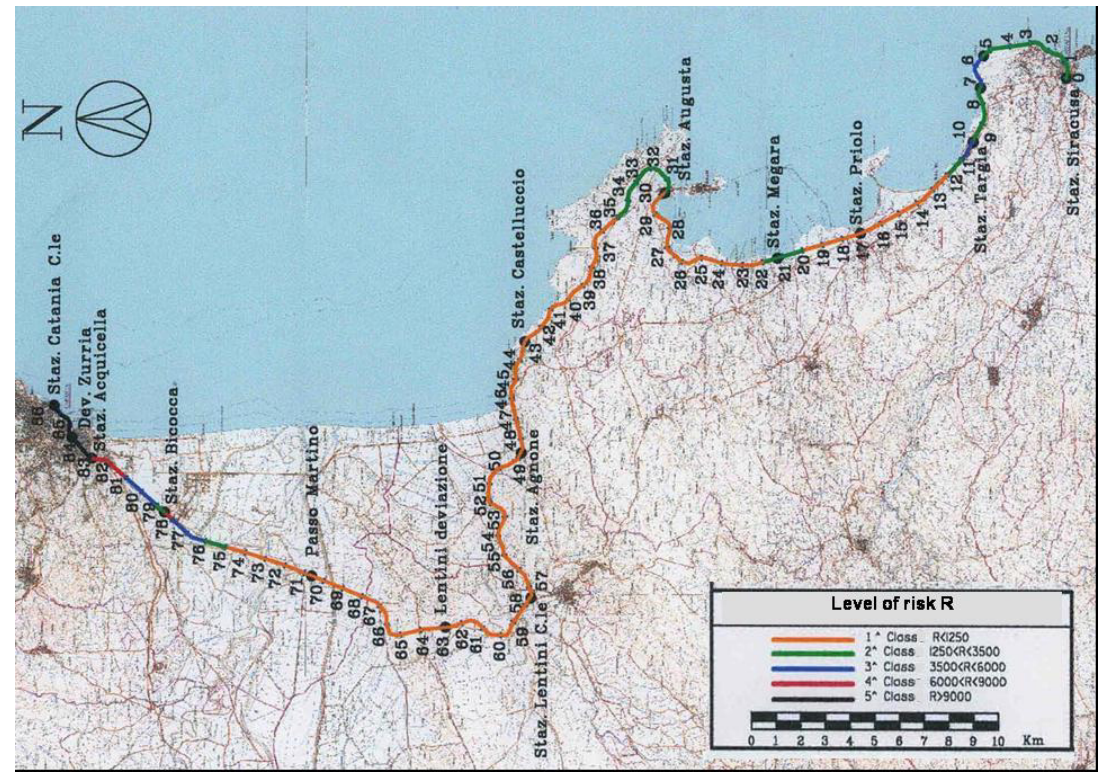

Figure 4: $\quad$ Level of risk $\mathrm{R}$ along the CT-SR line.

\section{Conclusions}

The study of risk connected to railway transportation of hazardous materials was approached with reference to the traditional evaluation procedures which take into consideration the risk generated by the product of danger, vulnerability and exposure. The first two factors were defined with specific reference to the methods and characteristics of railway transport together with the kind of wagon, railway operation and the characteristics of the stretch of line. 
More particularly, as regards the attribution of weights to the various causes of accidents, the model was calibrated to the data gathered from international sources which, although guaranteeing a general validity could mean that it does not completely correspond to specific national conditions.

The exposure factor was defined so as to permit an assessment of the extent of the damage in terms of the exposed population and is, therefore, connected to the population distribution in the area around the railway line and the extent of the diffusion of the harmful consequences of the accident.

Finally, the use of a case study made it possible to confirm the efficiency of the procedure in providing the various levels of risk associated to the various parts of a journey over the whole of the line.

The quantification of risk carried out using the proposed procedure proved to be particularly suitable both for evaluating the efficiency of relief interventions/improvement works on the stretches most at risk and for carrying out comparative analyses on alternative routes or other forms of transport [11].

\section{References}

[1] P. Haastrup, L. Brockhoff - Severity of accidents with hazardous materials - J. Loss Prev. Process Ind. - vol.3, ottobre 1990.

[2] A. Musso, O. Landolfi, L. Romanico - L'analisi e la valutazione della domanda di sistemi telematici per il trasporto merci pericolose su strada Ingegneria Ferroviaria, giugno 2003.

[3] RID - Regolamento concernente il trasporto internazionale ferroviario di merci pericolose - Direttiva 96/49/CE e successivi aggiornamenti.

[4] C.P.L. Barkan, C.T. Dick, R. Anderson - Analysis of railroad derailment factors affecting hazardous materials transportation risk - TRB Annual Meeting 2003.

[5] Velli-Pekka Kelberg - Risk analysis of Finish railways - TRB Annual Meeting 2002.

[6] R. Anderson, C.P.L. Barkan, - Railroad accident rates for use in transportation risk analysis - TRB Annual Meeting 2004.

[7] L. Brockhoff - A risk management model for transport of dangerous goods - EUR 14675 EN, 1992.

[8] RFI Direzione Manutenzione - Rilievi della geometria del binario e relative disposizioni manutentive - 1992 .

[9] B. Mazzarotta, R. Bubbico, G. Spadoni - Definizione di un indice di rischio per il trasporto di merci pericolose - VGR 2004.

[10] C. Cannalire et al. - Risk analysis for the transportation of LPG by road and rail, Loss Prevention and Safety Promotion in the Process Industry vol. I, pp. 611-622., Elsevier Science B.V., Amsterdam 1995.

[11] S. Cafiso, F. Colombrita - Un modello di valutazione del rischio per il trasporto su strada di merci pericolose - XI convegno SIIV, Verona 2001. 